\title{
Application and Practice of Drucker's Self-management Thought in Document Management
}

\author{
Xu Xin ${ }^{\mathrm{a}, *}$, Wen Yu \\ Sichuan Institute of Solid State Circuits, China Electronics Technology Group Corp., Chongqing 400060, P. \\ R. China \\ a shenlandehai@126.com \\ *corresponding author
}

Keywords: self-management, self-realization, application, document management.

\begin{abstract}
Starting from Drucker's "The Effective Executive", this paper first discusses what selfmanagement ideas are, why they need self-management, and self-management content, and then combines practical work to explore the specific application of self-management in document management positions. And practice, combined with self-management thinking, it put forward their own views on the medium and long-term progress and planning of the work.
\end{abstract}

\section{Introduction}

Self-management is both an innovative management concept and model, and an art of discovering self-worth, which is very useful for society, businesses and individuals. Selfmanagement is the highest level of management and is the most economical and effective management method. It can make society and enterprises reduce the money and time cost for managers. It has certain improvement on the management effect of the state and enterprises. value. Self-management is even more crucial to human success. It is the foundation and path of success in life. "The Father of Management," said Peter F.Drucker, "In the knowledge economy, success belongs to those who are self-managed."

\section{Drucker's Self-management Thought}

The "Effective Executive" is the earliest discussion of the management of self-management systems. In this book, Drucker mainly discusses seven aspects: effectiveness can be learned, mastering his own time, what I can contribute, exerting his strengths, important prior preparation, decision-making elements and effective decision-making. Self-management of effective managers. Drucker's self-management thinking is mainly reflected in the following four aspects:.

\subsection{Everyone should manage themselves}

Drucker believes that not only do managers have to manage themselves, but employees also need to manage themselves, that is, everyone is actually a manager. This kind of self-management has both practical methods that can be applied to specific situations, as well as the meaning of career management throughout life. Therefore, it has the meaning of human management, and selfmanagement, self-improvement and self-realization together constitute a complete process based on self-management.

\subsection{Self-management is the embodiment of humanism}

Drucker's self-management thought embodies the characteristics of humanism from the following four aspects: purpose, that is, self-management realizes the meaning and overall development of the individual's life. Subjectivity, through self-examination and self-evaluation, evokes the individual's subjective consciousness and mobilizes individual autonomy, enthusiasm and originality. Responsibility, personal choice is based on their own duties and responsibilities and 
recognition of social values. Effectiveness and effective self-management enable management individuals to maximize their potential and strengths and seek comprehensive self-development.

\subsection{Self-management is the way to self-realization.}

The real existence of man is not that he is a certain established thing, but that he wants to constantly realize what he wants to be, and constantly update himself to make himself the kind of person he wants to become. It is only possible to achieve in the self-management of individuals. Drucker's self-management thought extends the meaning of management from the organizational level to the individual, and emphasizes the decisive significance of self-management in individual development and self-improvement. Therefore, his self-management thinking is a breakthrough in human-centered management thinking.

\subsection{The main content of self-management}

Drucker's main contents of self-management are: (using feedback analysis) to understand their own strengths, what they should contribute (ie, what are the advantages), and how to behave (how to learn and reflect Performance), understanding your own values, understanding your own affiliation (and life goals), being responsible for relationships (and knowing how to interact with others), managing your second half (and career), time management and innovation management aspect.

\subsubsection{To understand their own strengths}

In the knowledge economy, success belongs to those who understand themselves, understand their own strengths, their own values, and how they perform best. The only way to discover your strengths is to conduct a feedback analysis. Whenever you make a major decision or take a major action, first write down what is expected to happen, and after 9-12 months, compare the actual results to your expectations. As long as you persevere, this simple method can show you your strengths and weaknesses in a relatively short period of time. The feedback analysis gives you the motivation for action: first, focus on your strengths; second, constantly improve your strengths and acquire new skills; third, discover your ignorance in knowledge and overcome them, rather than deceiving yourself. Correct bad habits that hinder your effectiveness and performance.

\subsubsection{What they should contribute}

To answer this question, you must know the following factors, what is the situation? What are your own strengths, expressions and values? How can you make the greatest contribution to what needs to be done? Finally, what results must be achieved in order to take advantage of it? The resulting course of action will be: what to do, where and how to start, what goals and deadlines to establish.

\subsubsection{How to behave}

The first point you should know here is whether you are a textbook or a listener. The second point is to understand how you should learn. There are many ways to learn, and you can learn in a way that you are good at. In addition, know whether you are a person who works with others or a loner. Trying to change yourself is unlikely to succeed, and efforts should be made to improve your learning and performance.

\subsubsection{Understanding your own values}

This is not a question of moral standards, but a question of "mirror inspection", which type of person you want to see in the mirror every morning. Your values conflict with the values of an organization. Then, if you work in this organization, you will either suffer setbacks or do nothing. Sometimes there is a conflict between one's values and their strengths, and values are the ultimate test. 


\subsubsection{Understanding your own affiliation}

This is essentially the management of the goals of self-life. Once people manage their self-goals and prepare for opportunities, successful careers begin to develop because they know their strengths, their working methods and their own values. Knowing what a person belongs to can make an ordinary person a person with outstanding performance.

\subsubsection{Being responsible for relationships}

In order to be effective, you must understand the strengths, expressions and values of your colleagues, because everyone works in his own way. Then you must be responsible for communication and communicate with your colleagues. Today's organization is based on mutual trust.

\subsubsection{Managing your second half}

When you have been working for many years, you may be bored and face a middle-aged crisis. In fact, you may still face another year of work. This is a good time to start your second career. Developing a second level of interest is not only a hobby, but also an opportunity to be a leader, respectable, and successful.

\subsubsection{Time management}

Drucker believes that time management is "to get the right things done" and "to do things right". This kind of time management also reflects the performance management of a person. "You can't manage time, you can't manage anything." "To say that effective managers are different from others, the biggest difference is that they cherish their time." "Time is the most scarce resource. If you don't manage your time, you need to manage other things. Other things, that's just empty talk."

\subsubsection{Innovation management aspect}

"The only eternal law in human activities is change. Therefore, only those companies that are satisfied with today will find it difficult to survive in a uncertain tomorrow." Drucker's conclusion is: "No innovation, Desperate."

\section{Self-management Practice at Work}

Document management work often faces cumbersome coordination and communication work. In many cases, the time schedule caused by the project leader's lack of attention to the document work lags behind, and the document management personnel and the project leader are pushing each other's authority, and the work recommendation is slow.

Through the self-management learning within the document management team, the shortcomings are found internally, and self-management teams are built from the perspective of self-improvement.

\subsection{Self-management team}

The basic principle of a self-management team is to give the group and it's members sufficient autonomy. The members are also willing to make decisions independently on their own aspects. Different from the traditional way, the managers make decisions, but give the group a lot of autonomy. Many decisions need to be made by members of the group. He also believes that the characteristics of self-management teams are:

(1) Self-managed teams have a common team goal, and the common goal is to ensure a basic condition for team effectiveness;

(2) These team members have a lot of skills and increase the diversity, flexibility, and value of their skills by continuously learning new technologies;

(3) The team is usually responsible for the entire process or product, and of course the task is divided into team members;

(4) This team has an atmosphere that allows members to listen to each other and speak freely, which is conducive to fostering creativity and risk-taking. 


\subsection{Time management at work}

For the cumbersome and complex nature of document management, it is necessary to do a good job of time management.

The second part of the book "The Effective Executive" has a unique insight into time management. He said: "If you can't manage time, you can't manage anything." "To say that effective managers are different from others, the biggest difference is that they love their time." "Time is the most scarce resource. If you don't manage your time, you need to manage it. Other things, that's just empty talk." Time management is the use of scientific methods and techniques to improve the utilization and effectiveness of time.

The theory of time management emphasizes that the object of time management is not "time" but "self-management" for time. In Drucker's words, time management is "to get the right things done" and "to do things right". Among them, "to get the right things done" means to use time in the positive direction, with as little waste as possible (this is "effective" or "effect"), and "to do things right" means to "make more in the implementation process" Fast, good, and provincial, try to improve the effectiveness of time. Therefore, the key to time management is "to get the right things done". To be able to "to get the right things done", you must manage the self-use of time, reduce time wastage, in order to effectively complete the established aims.

How to make full use of time and how to get the most benefit in the shortest time is not only an important part of the work, but also a problem that everyone who wants to do something in their career should pay full attention to. In the past, in order to complete the work, more choices were made for endless overtime. Time management can improve the use efficiency of time, optimize the sorting of work, grasp the key, balance the role, and improve work efficiency.

\section{Thoughts on Document Management Work}

The secret of the time management of successful people is to do tomorrow's work today. As long as you are prepared, you can cope with the future and seize the opportunity. As for how to carry out effective management time, do tomorrow's business today, and prepare for the future opportunity, Peter Drucker made a brilliant description in the second part of "The Effective Executive": "According to my observation, Effective managers often do not start with tasks, but start with time.

Instead of planning first, we first identify the actual places of time, then they try to manage their time, reduce those ineffective time requirements, and finally they integrate the scattered time into large blocks of continuous time units. Mr. Drucker's revelation is that time management should start with "knowing where you are going", which is the starting point for time management processes and steps, and the entry point for other tasks and tasks.

In the daily work, we must carry out self-management, but also combine the goals of the entire team and department, do the work ahead, recommend the standardization of documents, recommend excellent document templates, and strictly establish the time-node evaluation mechanism for document writing, which is not only beneficial to the entire department. Standardized construction of documents, reducing duplication of work caused by format confusion, irregular forms, etc., is also conducive to reducing the burden of designers writing documents.

\section{References}

[1] M Francis WM. Cheung, Yin Cheong Cheng. An Outlier Study of Multilevel Self-Management and School Performance [J]. School Effectiveness and School Improvement, 2002, Vol. 13, No. 3:253-290.

[2] B Jasmin Tada, Sameer Prasad. Team self-management, organizational structure, and judgements of team effectiveness [J]. Journal of Managerial Issues, Volume 16, Nov 2, 2004: 248265.

[3] Kate R. Long, Halsted R. Holman. Self-management education: history,definition, outcomes, and mechanisms [J]. The Society of Behavioral Medicine,Volume 26, Nov.l, 2003:1-7. 